\title{
Trastornos de la Conducta Alimentaria y Estilos Parentales
}

\author{
Analia Veronica Losada ${ }^{1}$ \\ Agustina Charro ${ }^{2}$ \\ analia_losada@yahoo.com.ar \\ Rec. 14/10/2017, Apr. 09/02/2018
}

\begin{abstract}
Resumen:
Los trastornos alimentarios son patologías altamente frecuentes en mujeres jóvenes, y según la literatura el funcionamiento familiar juega un rol importante tanto en su desarrollo como en su curso y evolución. La presente investigación tuvo como objetivo principal caracterizar la percepción que tienen las pacientes con un Trastorno de la Conducta Alimentaria del Estilo de Crianza prevalente en su entorno familiar, e investigar cómo podría asociarse esto con el desarrollo de la patología. La muestra estuvo compuesta por 16 pacientes del Instituto Argentino de Trastornos de Alimentación, cuyas edades oscilaban entre 12 y 21 años, 4 de ellas padecían Anorexia, 8 Bulimia y los 4 restantes Trastorno de la Conducta Alimentaria No Especificado (TANES). Se aplicó una adaptación de la Escala Argentina de Percepción de la relación con los padres de Richaud de Minzi (2002), para evaluar el tipo de estilo de crianza prevalente en cada cuadro. Para complementar estos resultados, se hizo una revisión de las historias clínicas de las pacientes y se administraron a su vez una serie de entrevistas a los profesionales que atendían a estas pacientes, conformado por psicólogo, nutricionista, y médico clínico. Los principales hallazgos dan cuenta de que existe un Estilo de Crianza preponderante en cada Trastorno Alimentario, es decir en la Anorexia reina un Estilo Permisivo, en la Bulimia un Estilo Autoritario y en los TANES un Estilo Indiferente.
\end{abstract}

\begin{abstract}
:
Eating disorders are highly frequent pathologies in young women, and according to the literature family functioning plays an important role both in its development and in its course and evolution. The main objective of the present investigation was to characterize the perception of patients with Eating Habits Disorder of the Critical Style prevalent in their family environment, and to investigate how this could be associated with the development of pathology. The sample consisted of 16 patients from the
\end{abstract}

1 Universidad Católica Argentina. Psicopedagoga. Lic. y Dra. Psicología.Especialista y Magíster en Metodología de la Investigación.Especialista en Psicología Clínica con Orientación en Docencia e Investigación. Pos Doctora en Psicología.

2Esta investigación formó parte de su trabajo de integración final para la obtención del título de Lic. en Psicología. Universidad Católica Argentina. 
Argentine Institute of Eating Disorders, whose ages ranged from 12 to 21 years, 4 of them suffering from Anorexia, 8 Bulimia and the remaining 4 Disorders of Unspecified Food Behavior (TANES). An adaptation of the Richaud de Minzi (2002) Argentine Perception Scale was applied to evaluate the type of parenting style prevalent in each table. To complement these results, a review of the patients' clinical histories was carried out and a series of interviews were administered to the professionals who attended these patients, consisting of psychologist, nutritionist, and clinical doctor. The main findings are that there is a predominant Fostering Style in each Eating Disorder, that is, in Anorexia, a Permissive Style reigns, in Bulimia an Authoritarian Style, and in TANES an Indifferent Style.

\section{Delimitación del Objeto de estudio}

En esta investigación se desarrollará la temática de los estilos de crianza en relación a los diferentes tipos de Trastornos de la Conducta Alimentaria. Según la teoría sistémica, la cual considera a la familia como un sistema, la misma estaría compuesta por un conjunto de personas que interaccionan de una manera dinámica particular, donde lo que le pasa a un miembro repercute en los otros y en el grupo y viceversa. Desde la perspectiva de este enfoque entonces es esencial trabajar en conjunto con la familia durante el tratamiento de las pacientes con Trastornos de la Conducta Alimentaria y sería fundamental la contención y el apoyo por parte de la familia para el miembro enfermo (Ortiz Gómez, 1999). La investigación que se va a llevar a cabo se va centrar en hacer una evaluación sistémica de los Trastornos de la Conducta Alimentaria con el fin de conocer cómo es el estilo de control parental característico en cada uno de los diferentes Trastornos de la Conducta Alimentaria (la Anorexia, la Bulimia y los Trastornos de la Conducta Alimentaria No Especificados).En primer lugar se explorará si existe un estilo de crianza propio en cada uno de ellos, y luego se investigará la asociación que tiene éste en el desarrollo de los diferentes Trastornos de la Conducta Alimentaria. A su vez se explorará qué papel juega éste en su constitución. De este modo los resultados permitirán conocer las convergencias y divergencias que existen entre las familias de los diferentes tipos de trastornos alimentarios y de ahí la necesidad de hacer diferentes intervenciones terapéuticas en cada caso. Además, este estudio, podría dar cuenta de la necesidad de trabajar en conjunto con la familia durante el tratamiento de las pacientes con alteraciones de la conducta alimentaria, haciendo intervenciones tanto a nivel individual como familiar, las cuales apunten a tratar por un lado el Trastorno Alimentario en sí mismo y por otro lado modificar el estilo de control parental y de este modo modificar la dinámica de esa familia. Asimismo, conocer estos datos acerca de los estilos de crianza, podría contribuir para investigaciones futuras que apunten a desarrollar algún programa de prevención para las familias contra los trastornos alimentarios.

\section{Familia}

La familia es algo autoconstitutivo, que funda los primeros estadios evolutivos de los que, en buena parte, dependerá el futuro de la trayectoria 
biográfica por la que se opte. Ello, en cierto modo, condicionará una accesibilidad mayor o menor al propio destino personal, a la autorrealización como persona, a la conquista de la felicidad. (Ruiz Martínez, 2010, p. 5) ${ }^{3}$

Dado que las primeras bases del ser humano se dan en la familia, es de suma importancia el estudio de la misma y el análisis del funcionamiento familiar, el cual es conveniente analizar desde un enfoque sistémico, ya que la familia es un grupo o sistema compuesto por miembros que son sus subsistemas, que a su vez forma parte de un sistema mayor que es la sociedad. Desde esta perspectiva, cualquier alteración que se presente en uno de los miembros de la familia repercute inevitablemente en los otros y en el funcionamiento total del grupo, es así que la presencia de una enfermedad en un miembro requiere que toda la familia modifique su dinámica para cuidar del mismo, siendo así necesaria la intervención tanto a nivel individual como familiar durante el tratamiento. Concebir a la familia como un sistema supone ver a la misma como una unidad donde se dan un conjunto de interacciones que dan lugar a una totalidad. Es por esto que los problemas familiares deben ser vistos como disfunciones en la interacción familiar, es decir que el miembro que expresa una enfermedad o patología es el representante de una falla en la dinámica familiar por lo que debe ser entendido y abordado el problema desde esta perspectiva (Ortiz Gómez, 1999).

La familia, en tanto que es un ámbito de aprendizaje, puede actuar como factor etiológico, como factor mantenedor o factor protector de los síntomas de una enfermedad. Puede operar como factor etiológico dado que el funcionamiento disfuncional de la misma puede dar lugar a diferentes trastornos, como factor mantenedor en el sentido que las perturbaciones en las interacciones entre sus miembros hacen que los síntomas persistan en el tiempo. Como factor protector sería el caso donde la familia le brinda a sus miembros los recursos y herramientas necesarias para hacer frente a los factores de riesgo (Ruiz-Martínez et. al., 2010). Como se dijo previamente la disfuncionalidad en una familia puede dar lugar al desarrollo de determinados síntomas, al desenlace de crisis o incluso puede agravar algún trastorno ya presente, haciendo que este se consolide, volviéndose así crónico. Si aún durante el tratamiento, el funcionamiento familiar no mejora éste puede llegar a ser un obstáculo para la evolución del mismo (Ortiz Gómez, 1999).

Según D. D. Jackson (1971), un miembro de una familia es solo relativamente independiente, dado que responde inevitablemente a las evaluaciones de los otros miembros, además existe un intercambio permanente de mensajes relacionales entre ellos que caracterizan a una familia en función de las maniobras que ésta emplea. De aquí se desprende la necesidad de hacer terapia conjunta con todo el grupo familiar, ya que puede resultar imposible el progreso en psicoterapia de un miembro particular si se prescinde del resto de los integrantes de la familia. Cabe destacar que la manera en que la propia familia de un sujeto promueve o desalienta sus maniobras durante la infancia, determina positiva o negativamente la capacidad del individuo para interactuar en diversos tipos de relaciones en su adultez. Pues el niño aprende a utilizar a sus padres como modelos de la manera en que se debe responder. Es de suma importancia para el terapeuta evaluar el tipo de interacción familiar ya que lo ayudará a planificar el tratamiento, para esto es necesario ver cómo es la comunicación interfamiliar, ya que nos da una pauta de qué manera el paciente llegó a serlo y cuán iatrogénico puede resultar para los otros integrantes, el tratamiento del paciente en forma individual. 
Pichon Riviere (1970), sostiene que la salud mental de un sujeto puede entenderse en términos de la calidad del comportamiento social. Este comportamiento está determinado de manera positiva o negativa, por aspectos de orden socioeconómico y familiar. Dado que un enfermo mental es el portavoz de los problemas y tensiones de su grupo más inmediato, la familia y a su vez es el depositario de los aspectos alienados de su estructura social. Para su sanación es necesario concederle un nuevo rol, el de agente de cambio. Es de suma importancia considerar la naturaleza instrumental y operativa de la familia como sostén de la organización social, unidad primaria de interacción, es el instrumento socializador por excelencia, dentro del cual el individuo adquiere su posición individual dentro de la red interaccional. La familia es la mediadora entre el sujeto y la realidad.

El grupo familiar tiene un carácter de estructura, el cual nos permite abordar al mismo como unidad de análisis, ya que nos podemos acercar a él, en términos de unidad diagnostica, pronostica, terapéutica y de profilaxis. De aquí que se entiende a la conducta patológica de un miembro como una anomalía que afecta a la estructura total. Como se dijo anteriormente el miembro enfermo es el vocero de una situación patológica implícita que se está viviendo en esa familia, es el depositario de la ansiedad del grupo (Riviere, 1970).

Una crisis a nivel familiar, como puede ser la patología de uno de sus miembros, puede resultar una oportunidad para el crecimiento y maduración de esa familia o puede que la haga más vulnerable, manteniendo su integridad mediante recursos negativos. En esta última instancia es que se vuelve decisiva la necesidad de asistencia del grupo familiar para promover un cambio saludable de sus relaciones. Puede venir la familia completa o no a terapia, los miembros que falten son respetados y tiene que ver esto con el papel que juegan los mismos en el ámbito familiar. Suele ser muy ventajoso ofrecer al resto de los integrantes la posibilidad de tener entrevistas individuales, ya que favorece y acelera la resolución del conflicto que se trabaja simultáneamente a nivel grupal e individual. La meta en el tratamiento de las crisis familiares es brindarle a la familia la posibilidad de convivir en un clima de trabajo positivo que les permita resolver las dificultades que le imposibilitaron resolver la situación conflictiva (Moreno \& Kusmin, 1970).

\section{Estilos de Crianza}

Los estilos de crianza se circunscriben al marco de la familia, se desarrollan dentro de la misma y son puestos en práctica por los padres con el fin de educar, influir y orientar a sus hijos para que puedan integrarse socialmente, por medio de estos estilos de control los padres intentan inculcar en sus hijos ciertos valores y normas (Ramírez, 2005). Coll, Miras, Onrubia y Solé (1998) sostienen que estas prácticas educativas familiares son exclusivas y específicas de cada familia, pero al mismo tiempo son también similares a las que utilizan otras familias del mismo grupo social. Se los llama estilos ya que perduran en el tiempo y mantienen cierta estabilidad y a través de ellos los padres intentan guiar las conductas de sus hijos en determinada dirección, influenciando así en las respuestas que dan los mismos ante las situaciones cotidianas. Estas prácticas educativas parentales estarían determinadas por la confluencia de una serie de factores, entre ellos están las características del niño, las características de los padres y el contexto en donde se da la interacción entre ellos, es decir la estructura familiar (Ramírez, 2005). 
En este sentido, los cambios que se dan dentro de una familia, en su estructura y dinámica, pueden tener un efecto sobre los estilos parentales de educación y sobre el desarrollo socioafectivo de sus hijos en la infancia. Asimismo, como se dijo previamente, existen numerosos factores biopsicosociales que afectan los estilos de crianza y las interacciones con los hijos, por lo cual se vuelve necesario identificar, por un lado los factores de riesgo, para trabajar sobre ellos y así erradicarlos y por otro, los factores protectores para la salud mental de los niños, con el fin de promoverlos. De esta manera, es importante tener en cuenta que los estilos de crianza inapropiados de los padres durante la infancia se consideran factores de riesgo de problemas cognoscitivos o socioafectivos, por lo que las estrategias de prevención deben estar dirigidas a la familia y a su vez generar espacios para desarrollar habilidades sociales y actividades prosociales en otros contextos. Es así que cada familia asume los estilos de crianza en función de sus características, dinámica, factores del contexto, recursos y apoyos con los que cuenta (Cuervo Martínez A., 2010).

Henao, Ramirez \& Ramirez (2007) aseveran que la combinación de las costumbres y prácticas de crianza de los padres, la sensibilidad hacia las necesidades de su hijo, la aceptación de su individualidad y la del otro, el afecto expresado, los mecanismos de control ejercidos y el tipo de disciplina aplicado, sientan las bases de las estrategias de socialización utilizadas por los padres para regular el comportamiento de sus hijos, haciendo especial hincapié en la importancia de la comunicación en las pautas de crianza. A su vez, estos autores sostienen que por medio de las prácticas educativas familiares se logra descifrar la dinámica de una familia, dado que en ellas se pone en evidencia el pensamiento de los padres respecto a la norma, la autoridad, el afecto, el control, la comunicación, entre otros, su incidencia en los hijos y en las relaciones entre ellos.

Cabe destacar que los padres de niños entre 5 y 8 años de edad no tienen aún un estilo de crianza definido, lo cual debe considerarse como punto importante a la hora de hacer intervenciones que apunten a la modificación o mejoramiento de los mismos (Torío, Peña y Caro, 2008).

Richaud de Minzi (2002) afirma que la calidad de la interacción entre el padre y la madre y sus hijos es uno de los factores determinantes de la conducta infantil y del desarrollo de la personalidad. Es por esta razón que cuando se evalúan las características de personalidad en un sujeto adulto, se indaga siempre sobre cómo fue su relación temprana con cada uno de sus padres. El estilo de crianza, es decir la conducta de su madre y padre durante su infancia, está relacionado con el ajuste de la personalidad, la creatividad y la normalidad del comportamiento de ese individuo. A su vez, el tipo de relación con la madre y el padre tiene un efecto en el desarrollo de los recursos de afrontamiento: el apoyo social, el locus de control y la confianza interpersonal. La autora hace hincapié en que en realidad la capacidad de adaptación de una persona depende más, de la percepción que ésta tiene acerca del comportamiento de su madre o padre, que del comportamiento "real" de sus progenitores.

De esta manera, se tornan esenciales las relaciones, tanto con el padre como con la madre, como la participación activa de ambos progenitores en la crianza, la disponibilidad y el grado de apoyo que percibe el hijo, y a su vez la primacía de una buena comunicación, que brinde apoyo instrumental y afectivo a la prole. Convirtiéndose así en pilares primordiales de la crianza, las dimensiones de control, afecto y grado de implicación en la educación de los hijos, siendo éstas las variables que mejor predicen un buen estilo educativo y la calidad del vínculo paterno-filial (Mestre,Tur, Samper, Nácher y Cortés, 2007). 
Baumrind (1973, citado en Ceballos \& Rodrigo, 1998) diferencia cuatro estilos de crianza: el autoritario, el democrático, el permisivo y el indiferente. Puede que el comportamiento de algunos padres no encaje exactamente en uno de los principales patrones descritos, pero seguramente se asemeje a uno u otro.

Estilo autoritario: estos padres ejercen un estricto control y exigen un elevado nivel de madurez a sus hijos, lo que va acompañado de una pobre comunicación y escasa expresión emocional. Lo que caracteriza a este patrón de crianza son las excesivas normas y las exigencias estrictas, las cuales están basadas en patrones rígidos preestablecidos y les cuesta moverse de ellos. Prima la obediencia de las normas y en caso de no cumplirse, recurren al uso del castigo sin dar lugar al diálogo.

Estilo democrático: estos progenitores presentan altos niveles de comunicación, afecto, control y exigencias de madurez. Si bien ejercen el control, tienen en cuenta las necesidades y sentimientos de sus hijos, siendo así más empáticos y flexibles. Dan explicaciones de sus comportamientos y exigencias, ponen límites los cuales orientan a sus hijos, pero a su vez están dispuestos a escucharlos y llegar a un acuerdo mutuo. Según la bibliografía este patrón es el que mejor promueve el desarrollo de la personalidad en los hijos, brindándole seguridad y confianza en ellos mismos, así como habilidades comunicacionales y de socialización.

Estilo permisivo: estos padres ejercen poco control y tienen bajas exigencias de madurez, pero a diferencia de los autoritarios estos progenitores se caracterizan por un alto nivel de comunicación y afecto. Prima el "dejar hacer", aceptan la conducta de su hijo y no le ponen límites ni castigo, no hay normas que estructuren la vida del nińo, sino que por el contrario consultan a sus hijos sobre decisiones, rechazando el ejercicio de poder y de control sobre el mismo.

Estilo indiferente: estos padres parecen ser indiferentes ante sus hijos, no son ni exigentes ni receptivos, no ejercen ningún tipo de control ni exigencias de madurez y los niveles de comunicación y afecto son muy bajos, dejando así a sus hijos a la deriva. Son padres negligentes, les dan a sus hijos tan poco como lo que les exigen.

El estilo de crianza hace al funcionamiento familiar y la calidad del mismo juega un rol importante tanto en el desarrollo, como en el curso y resultado de los trastornos que puedan presentarse en la familia (Cook-Darzens et al., 2005, citado en Cruzat, Ramirez, Melipillán \& Marzolo, 2008). Un ambiente familiar adverso puede ser caldo de cultivo de una enfermedad, como pueden ser los Trastornos de la Conducta Alimentaria (Leija Esparza, Sauceda García \& Ulloa Flores, 2011).

\section{Trastornos de la Conducta Alimentaria}

Los Trastornos de la Conducta Alimentaria se podrían definir como alteraciones en la conducta relacionadas con la actitud y el hábito de comer, consecuencia de los esfuerzos excesivos por controlar el peso y la silueta y el temor desmedido a engordar (Cruzat et al., 2010). Según el DSM-IV-TR los trastornos de la conducta alimentaria, se clasifican en: Anorexia Nerviosa, Bulimia Nerviosa y Trastornos de la Conducta Alimentaria 
no especificados (American Psychiatric Association. (1993). Diagnostic and Statistical Manual of Mental Disorders (4th ed.). Washington, D.C: American Psychiatric Association). Igualmente, estos cuadros están relacionados entre sí, compartiendo ciertos rasgos clínicos y observándose en muchos casos durante su evolución la migración de un trastorno a otro. Lo que caracteriza y comparten los tres cuadros es el temor a engordar y la preocupación por la imagen corporal, lo cual les genera gran ansiedad (Marín 2002 en Cruzat et al. 2010). Las pacientes que padecen un trastorno alimentario presentan ciertas características en determinadas áreas:

1. Aspectos psicológicos: mayor insatisfacción y dificultades en la capacidad para afrontar, conflictos en relación a eventos sociales y miedo a perder el control emocional.

2. Conducta de comer: disgusto al ser vistas mientras comen, inquietud por los alimentos y miedo a perder el control al comer.

3. Imagen corporal: preocupación por la silueta y el peso y temen perder el control sobre su cuerpo (Cruzat et al. 2010).

La Anorexia Nerviosa es un trastorno de la conducta alimentaria que se define por un miedo intenso a ganar peso, por lo que el enfermo recurre a diferentes tipos de conductas patológicas para lograr su objetivo, que es bajar de peso. Esto puede conducir, en ocasiones, a un estado de inanición, es decir una situación de gran debilidad provocada por una ingesta insuficiente de nutrientes esenciales. Para el diagnóstico de este trastorno es a su vez necesaria la presencia de una alteración significativa de la percepción del propio cuerpo (American Psychiatric Association, APA, 2002, citado en Cruzat et. al. 2008).

La Bulimia Nerviosa se caracteriza por la recurrencia y repetitividad de episodios en los que el enfermo come de manera excesiva y desproporcionada (atracones) una cantidad de comida mucho mayor a la que comería la mayoría de la gente en un período muy corto de tiempo. Luego intenta compensar esto, recurriendo a diferentes tipos de conductas purgativas inapropiadas, como el vómito autoinducido, el abuso de laxantes y diuréticos, el ayuno drástico y/o el hacer ejercicio compulsivamente, con el fin de controlar su peso (American Psychiatric Association, APA, 2002 en Cruzat et. al. 2008).

Por su lado los Trastornos de la Conducta Alimentaria No Especificados son trastornos de la conducta alimentaria que no cumplen todos y cada uno de los criterios necesarios para ser diagnosticados como un trastorno típico de la conducta alimentaria, Anorexia o Bulimia (American Psychiatric Association, APA, 2002 en Cruzat et. al. 2008).

\section{Estilos de Crianza y los Trastornos de la Conducta Alimentaria}

Según la bibliografía, Osorio-Murillo \& Amaya-Rey (2011), la familia tiene una gran influencia en las creencias, en las prácticas y en la elección y consumo de los alimentos, es la creadora de las pautas de comportamiento en la alimentación, es por eso que los trastornos alimentarios podrían entenderse como un síntoma de la disfunción familiar cuanto mayor es la disfunción más grave sería el trastorno (Cruzat et. al. 2008). Dada esta condición se hace fundamental la inclusión de la familia en el tratamiento del mismo. Asimismo, hay que tener en cuenta las características de personalidad y patológicas de los padres de pacientes con un trastorno alimentario, ya sea como causa o consecuencia de la enfermedad que sufre su hija. Selvini Palazzoli, Cirillo, Selvini y Sorrentino 
(1999), afirman que los padres de las pacientes que padecen un Trastorno de la Conducta Alimentaria suelen negar tanto las frustraciones como los deficits que sufrieron en sus propias familias de origen, idealizando así a sus padres como a ellos mismos, no reconociendo sus fragilidades. A su vez estos padres tienden a evitar la comunicación con sus esposas, a sobrevalorar su trabajo y tiempo libre y a mantener distancia emocional y física respecto de sus hijos, todo esto estaría fomentado por la cultura machista prevalente. A esto se le suma que en sus propias infancias, estos padres recibieron escasa atención emocional, favoreciendo así la responsabilidad precoz en ellos (Espina Eizaguirre, 2005). Por este motivo, es esencial durante el tratamiento que el terapeuta empatice tanto con los padres como con la paciente y cree un clima de colaboración donde los progenitores no se sientan juzgados, haciendo intervenciones tanto a nivel individual como familiar para modificar así la dinámica y que toda la familia goce de un mayor y mejor estado de salud (Espina Eizaguirre, Ochoa de Alda Martínez de Apellániz \& Ortego Saenz de Cabezón, 2007).

Gedo y Goldberg (1973), enfatizan que estas familias son incapaces de modular la frustración, ansiedad, intromisiones dolorosas del medio o la sobreestimulación, ya sea que provengan de fuentes externas o internas, lo que trae consecuencias en el funcionamiento familiar general.

Brunch (1973), por su lado resalta que, en los casos de anorexia, existe entre la madre y la hija una relación temprana especial, en la cual hay un déficit de respuesta por parte de la madre ante las necesidades de la nińa.

Humphrey y Stern (1988), quienes se apoyan en la teoría de las relaciones objetales, sostienen que en las familias en las que hay un miembro que presenta un trastorno de la conducta alimentaria, los padres suelen fallar a la hora de brindar un ambiente parental contenedor. Por su lado Pole, Waller, Stewart \& Parkin-Feigenbaum (1988) concluyeron que los síntomas bulímicos estarían encubriendo un déficit del ego y esto estaría relacionado a su vez con una pobre empatía parental.

Stierling y Weber (1989), destacan la primacía del grupo familiar respecto del individuo en familias con un miembro con Trastorno de la Conducta Alimentaria y observaron en éstas, lealtad familiar y la negación de la individuación de sus miembros.

Rhodes y Kroger (1992), afirman que el estilo de control sin afecto maternal, el cual incluye la sobreprotección, inhibición de la individualidad, intrusividad, infantilización y la falta de calidez emocional, tiene mayor vinculación con el desarrollo de los trastornos de alimentación, que el paternal.

Rusell et. al. (1992), concluyen que la disfunción parental o la distorsión perceptual que tienen las pacientes enfermas acerca del vínculo con sus padres, o ambas cosas, puede ser una consecuencia del ambiente negativo presente en las familias con trastornos alimentarios. Las relaciones conflictivas entre padres e hijos, la constante emoción negativa, pueden actuar tanto como causa o consecuencia de las interacciones que preocupan tanto a los padres y afectan a su vez el desarrollo de los hijos. Es decir que un estilo de crianza inadecuado puede actuar como un factor predisponente a los trastornos de la conducta alimentaria.

Espina (2003), dice que la alexitimia como rasgo de personalidad de los padres de pacientes con Trastornos Alimentarios, puede influir en el desarrollo de sus estilos de crianza, ya que no brindan a sus hijas un modelo de procesamiento de las emociones adecuado, lo cual genera que ellas tengan dificultades en este área, lo cual es muy frecuente en los Trastornos de la Conducta Alimentaria. 
Vandereycken et. al. (1991), sostiene que las pacientes perciben el vínculo con sus madres como óptimo y con sus padres como frágil o ausente.

Selvini et. al. (1999), afirman que en las familias con trastornos de alimentación, la dificultad está en la tarea de proporcionar un espacio nutriente que tranquilice, que maneje la tensión con empatía y que de esta manera dé lugar al desarrollo de identidades separadas. De esta manera, tanto los padres como los hijos se verían "hambrientos" del calor emocional, de la ternura y del afecto genuino incondicional entre sí.

En un estudio realizado por Espina Eizaguirre et. al. (2007), se llegó a la conclusión de que la salud mental de los hijos está estrechamente relacionada con el modo en que los padres se vinculan con ellos. Cuando los padres tienen un adecuado tipo de cuidado sobre sus hijos, estos tienen una mayor probabilidad de ser niños sanos, mientras que cuando predomina la sobreprotección parental hay una mayor predisposición a contraer algún tipo de trastorno mental, es decir que la familia, los padres, "son una pieza clave para el desarrollo de sus hijos" (Espina Eizaguirre et al. 2007, p. 117).

\section{Objetivos}

- Referir la percepción que tienen las pacientes con un Trastorno de la Conducta Alimentaria del Estilo de Crianza prevalente en su entorno familiar, e investigar si podría asociarse esto con el desarrollo de la patología.

-Describir cómo es el Estilo de Crianza en pacientes con diagnóstico de Trastornos de la Conducta Alimentaria (Anorexia, Bulimia y Trastorno de la Conducta Alimentaria No Especificado) y ver qué papel juega éste en el desarrollo de la enfermedad.

- Analizar las diferencias existentes en los distintos cuadros de TCA acerca de los Estilos de Crianza.

\section{Hipótesis}

-Existen diferencias en la percepción del Estilo de Crianza en función del tipo de Trastorno de la Conducta Alimentaria.

\section{Método y tipo de Estudio}

Se llevó a cabo una investigación de índole empírica del tipo cualitativa en el Instituto Argentino de Trastornos de la Alimentación (Rafael Calzada, Buenos Aires, Argentina). Fue un estudio expost facto. La elección de este método refiere a que los fenómenos estudiados en las historias clínicas de los pacientes del Instituto Argentino de Trastornos de la Alimentación, es decir los diagnósticos de trastornos de la conducta alimentaria ya se habían dado con antelación. En este tipo de estudio los hechos son previos, ya están dados con antelación. E implica, a su vez, el estudio de los fenómenos bajo la pretensión de desarrollar las relaciones entre las Patologías Alimentarias y los Estilos de Crianza. Se intentó explicar los dos fenómenos y en qué condiciones se daría la relación de referencia. Se buscó el comprobar las hipótesis descriptas, analizar, sintetizar e interpretar los resultados y a través de ello contribuir al desarrollo del conocimiento científico.

\section{Participantes}

La muestra estuvo compuesta por 16 participantes de sexo femenino, cuya media de edad fue 17 años de edad. Cuatro pacientes (25\%) presentaron Anorexia, 8 (50\%) Bulimia y las 4 (25\%) restantes Trastorno de la Conducta Alimentaria No Especificado. 
Todas ellas pacientes asistidas en forma ambulatoria y en la modalidad de hospital de día en el Instituto Argentino de Trastornos de la Alimentación.

\begin{tabular}{|c|c|c|}
\hline Diagnostico & Frecuencia & Porcentaje \\
\hline Anorexia & 4 & 25 \\
Bulimia & 8 & 50 \\
TANES & 4 & 25 \\
\hline
\end{tabular}

Tabla 1. Diagnósticos de las pacientes

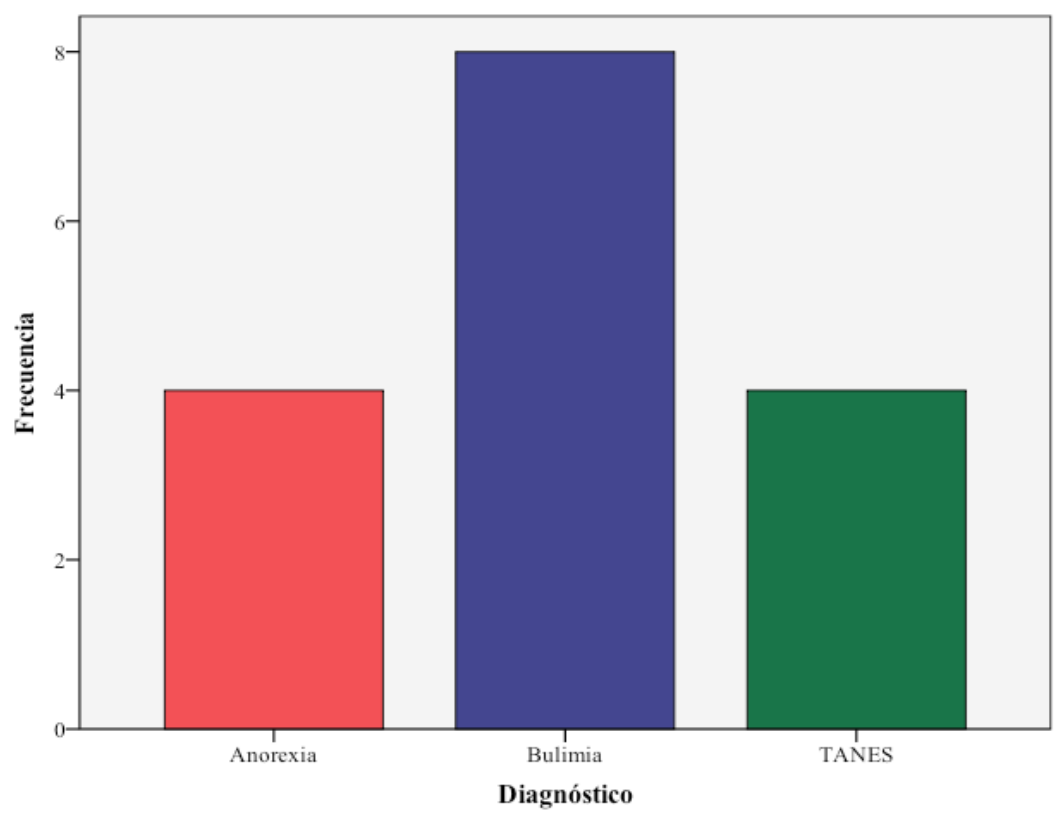

Grafico 1. Distribucion de los diagnósticos

\begin{tabular}{|c|c|c|}
\hline Edad & Frecuencia & Porcentaje \\
\hline 12 & 1 & 6,3 \\
13 & 1 & 6,3 \\
14 & 3 & 18,8 \\
16 & 3 & 18,8 \\
17 & 1 & 6,3 \\
18 & 2 & 12,5 \\
20 & 1 & 6,3 \\
21 & 4 & 25 \\
\hline
\end{tabular}

Tabla 2. Edad 


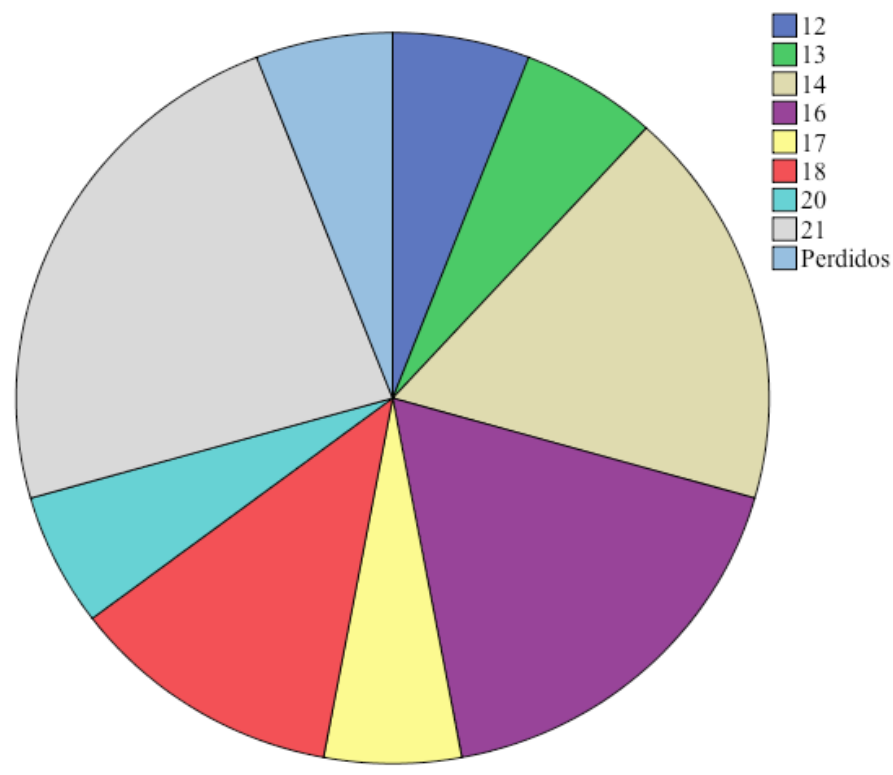

\section{Gráfico 2. Edad}

La institución fue fundada el 1 de mayo de 1999 y depende de la Asociación Civil Bienestar. Se encuentra habilitada por el Ministerio de Salud de la Provincia de Buenos Aires, por el Registro Nacional de Prestadores del Ministerio de Salud de la Nación y por el Municipio de Almirante Brown. Se halla emplazada en la localidad de Rafael Calzada, partido de Almirante Brown, al sur del gran Buenos Aires, aproximadamente a $30 \mathrm{~km}$ de la Ciudad Autónoma de Buenos Aires. Dentro del municipio conviven grupos con niveles de ingresos y estatus social muy diferenciados, fenómenos acentuados en las distintas localidades que conforman el distrito.

El mencionado establecimiento cuenta con un tratamiento ambulatorio y otro con la modalidad de hospital de día, cuya inclusión en uno u otro depende de la gravedad del caso. Los pacientes allí asistidos reciben terapia psicológica individual, terapia familiar, atención nutricional, asistencia médica clínica, consultoría médica psiquiátrica, atención psicopedagógica, acompañamiento terapéutico individual en la institución y en el domicilio del paciente y terapias individuales para algunos de los miembros del grupo familiar. Además, si el consultante asiste a hospital de día recibe almuerzo y merienda y realiza talleres en la institución. Los profesionales cuentan con experiencia en trastornos de la conducta alimentaria.

La población se encontraba evaluada bajo los criterios diagnósticos del DSM IV. Los pacientes cumplían con los criterios para la Anorexia Nerviosa, Bulimia Nerviosa o los Trastornos Alimentarios No Especificados (TANES). Durante la admisión, cada uno de los pacientes fue evaluado por un equipo multidisciplinario conformado por médico, psicólogo y nutricionista, con experiencia en patologías alimentarias. Los profesionales confeccionaron en cada caso una historia clínica con entrevistas semiestructuradas, que incluyeron la exploración, a través de preguntas abiertas y cerradas, de los antecedentes patológicos personales, familiares y de experiencias traumáticas previas al inicio de los 
trastornos de la conducta alimentaria. La indagación de antecedentes de intentos de suicidio o actos de daño deliberado autoinfligido, sus procedimientos, la frecuencia y el tiempo de evolución fueron explorados durante la entrevista, mediante preguntas directas. Del mismo modo, los profesionales médicos intervinientes solicitaron estudios de laboratorio u otros que estimaron necesarios en cada caso.

Con respecto al inicio del tratamiento, como se puede observar en la Tabla 3, un $6,3 \%$ de la población inició su tratamiento en el Instituto en el año 2009, otro 6,3\% lo inició en el año 2010, un 18,8\% lo comenzó en el año 2011 y el 68,8\% restante en el año 2012.

\begin{tabular}{c|c|c}
\hline Ańo & Frecuencia & Porcentaje \\
\hline $\mathbf{2 0 0 9}$ & 1 & 6,3 \\
$\mathbf{2 0 1 0}$ & 1 & 6,3 \\
$\mathbf{2 0 1 1}$ & 3 & 18,8 \\
$\mathbf{2 0 1 2}$ & 11 & 68,8 \\
\hline
\end{tabular}

Tabla 3. Inicio del tratamiento

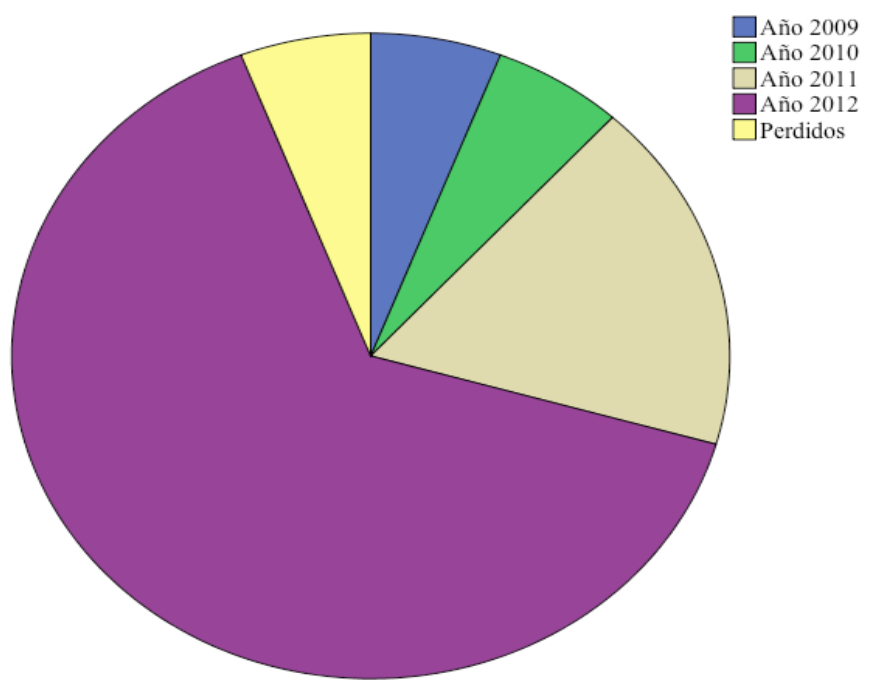

Gráfico 3. Inicio del Tratamiento

\section{Variables}

Las variables que se tuvieron en cuenta son Estilos de Crianza y Trastorno de la Conducta Alimentaria. Se evaluó cuál es el estilo de crianza predominante en cada caso, es decir cuál estilo de control parental impera en los diferentes trastornos: Bulimia, Anorexia y TANE. 


\section{Instrumentos de Recolección de Datos}

Se utilizó una adaptación de la Escala Argentina de Percepción de la relación con los padres de Richaud de Minzi (2002), la cual evalúa diferentes dimensiones que hacen a los diversos estilos de crianza, entre ellas: la aceptación, el control aceptado, el control estricto, el control patológico y la autonomía extrema, desinterés. Existe una escala para evaluar la percepción de la relación con cada padre, es decir que se administran dos escalas compuestas por 32 items cada una, una para evaluar la percepción de la relación con la madre y la otra con el padre.

\section{Procedimiento}

Se realizó el procedimiento correspondiente al consentimiento informado, para garantizar que la participación de todos los colaboradores fuese voluntaria y que los mismos fueran conscientes de los objetivos, los beneficios, las molestias, los posibles riesgos y las alternativas, sus derechos y responsabilidades, y asegurarse así el investigador, que los participantes han comprendido la información.

Luego se administró la adaptación de la Escala Argentina de Percepción de la relación con los padres de Richaud de Minzi (2002) a una muestra de 16 jóvenes, 4 con Anorexia, 8 con Bulimia, 4 con Trastorno de la Conducta Alimentaria No Especificado, para evaluar el tipo de estilo de crianza en cada una de ellas.

El paso siguiente fue una revisión de las historias clínicas de las pacientes atendidas en el Instituto Argentino de Trastornos de la Alimentación, en la cual se pudo obtener mayor cantidad de datos pertinentes a la temática evaluada.

A continuación, se entrevistó al psicólogo, a la nutricionista y al médico clínico de cada una de ellas.

Finalmente se evaluaron las convergencias y divergencias que hay entre ellas y se plasmaron los resultados en un cuadro de doble entrada.

\section{Resultados}

En función de los objetivos planteados, esta investigación logró cumplir con los mismos. En la Tabla 4 se muestran los resultados descriptivos obtenidos de la muestra.

\begin{tabular}{|cccc|}
\hline Caso & Diagnóstico & Estilo de Crianza Madre & Estilo de Crianza Padre \\
\hline 1 & Anorexia & Permisivo & Autoritario \\
2 & Anorexia & Permisivo & Autoritario \\
3 & Bulimia & Democrático & Autoritario \\
4 & Bulimia & Permisivo & Permisivo \\
5 & Bulimia & Autoritario & Autoritario \\
6 & Bulimia & Permisivo & Permisivo \\
7 & Bulimia & Democrático & Indiferente \\
8 & TANES & Autoritario & Democrático
\end{tabular}




\begin{tabular}{|cccc|}
9 & Bulimia & Democrático & Autoritario \\
10 & Bulimia & Autoritario & - \\
11 & TANES & Autoritario & Indiferente \\
12 & Anorexia & Permisivo & Autoritario \\
13 & Anorexia & Autoritario & Autoritario \\
14 & TANES & Indiferente & Indiferente \\
15 & Bulimia & Autoritario & Indiferente \\
16 & TANES & Indiferente & Autoritario \\
\hline
\end{tabular}

Tabla 4. Estilos de Crianza materno y paterno en cada caso según diagnóstico

De la lectura de los resultados obtenidos acerca del Estilo de Crianza materno que perciben las pacientes que padecen Anorexia (25\%), se halló que un $25 \%$ percibe un Estilo Autoritario y un $75 \%$ un Estilo Permisivo, no se han encontrado en este grupo presencia alguna de Estilo Democrático ni Indiferente.

En lo que respecta al grupo de pacientes que padece Bulimia (50\%), se observó que un 37,5\% percibe un Estilo Democrático, otro 37,5\% percibe un Estilo Autoritario y el $25 \%$ restante percibe un Estilo Permisivo, no se hallaron indicios de Estilo Indiferente en estas pacientes.

Por último, en el grupo de pacientes que padecen Trastorno de la Conducta Alimentaria No Especificado (25\%) se encontró que un 50\% percibe un Estilo Autoritario y el otro $50 \%$ percibe un Estilo Indiferente, no se han encontrado en este grupo pacientes que hayan percibido un Estilo Democrático ni Permisivo.

\begin{tabular}{|c|c|c|c|c|}
\hline & Democrático & Autoritario & Permisivo & Indiferente \\
\hline Anorexia & - & $25 \%$ & $75 \%$ & - \\
Bulimia & $37,5 \%$ & $37,5 \%$ & $25 \%$ & - \\
TANES & - & $50 \%$ & - & $50 \%$ \\
\hline
\end{tabular}

Tabla 5. Estilo de Crianza materno y Patologías Alimentarias 


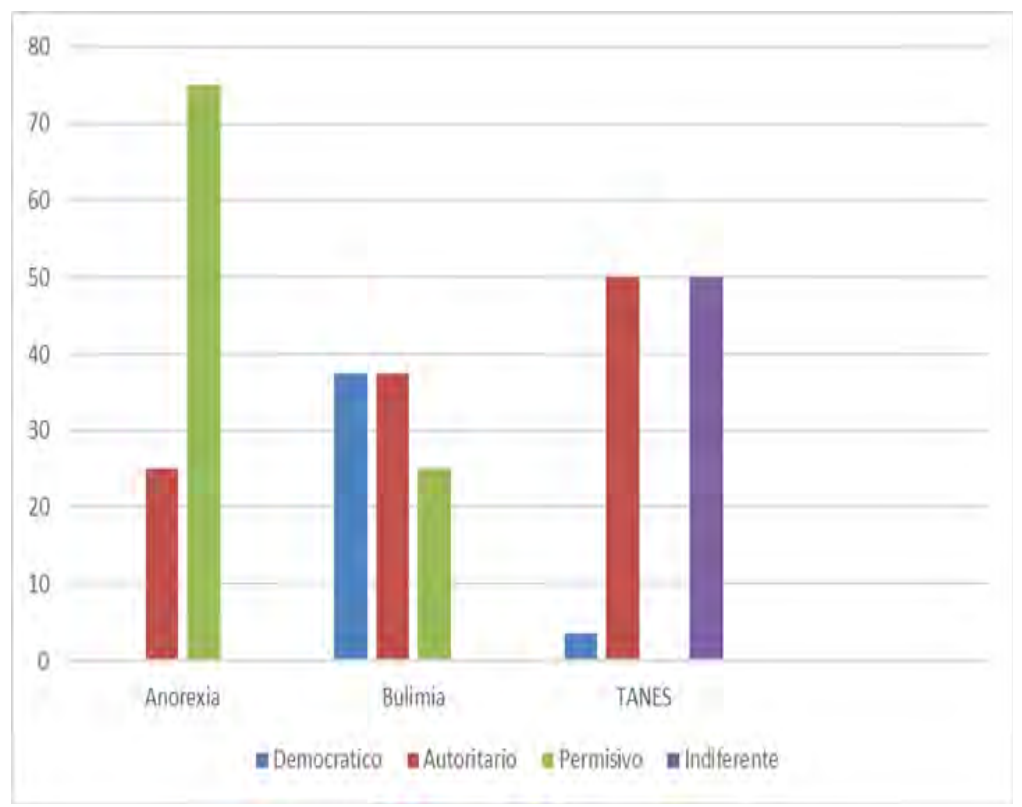

Gráfico 4. Estilo de Crianza materno y Trastornos de la Conducta Alimentaria

En lo que hace a los resultados obtenidos del Estilo de Crianza paterno, se pudo vislumbrar que en las pacientes que padecen Anorexia, un 75\% percibe un Estilo Autoritario y el 25\% restante percibe un Estilo Permisivo, no se han encontrado registros de Estil Democrático o Indiferente. Con respecto al grupo de pacientes que posee Bulimia, se halló que un 50\% percibe un Estilo Autoritario, un 12,5\% percibe un Estilo Permisivo y un 25\% percibe un Estilo Indiferente sin encontrarse rastros del Estilo Democrático. Dentro de este último grupo, cabe destacar que una de las pacientes es careciente de alguien que haya desempeñado el rol paterno. Dentro de las pacientes que padecen Trastorno de la Conducta Alimentaria No Especificado, se observó que un $50 \%$ percibe un Estilo Indiferente, un 25\% un Estilo Democrático y el 25\% restante un Estilo Autoritario, no se ha encontrado presencia alguna del Estilo Permisivo.

\begin{tabular}{|ccccc|}
\hline & Democrático & Autoritario & Permisivo & Indiferente \\
\hline Anorexia & - & $75 \%$ & $25 \%$ & - \\
Bulimia & - & $50 \%$ & $12,5 \%$ & $25 \%$ \\
TANES & $25 \%$ & $25 \%$ & - & $50 \%$ \\
\hline
\end{tabular}

Tabla 6. Estilo de Crianza paterno y Patologías Alimentarias 


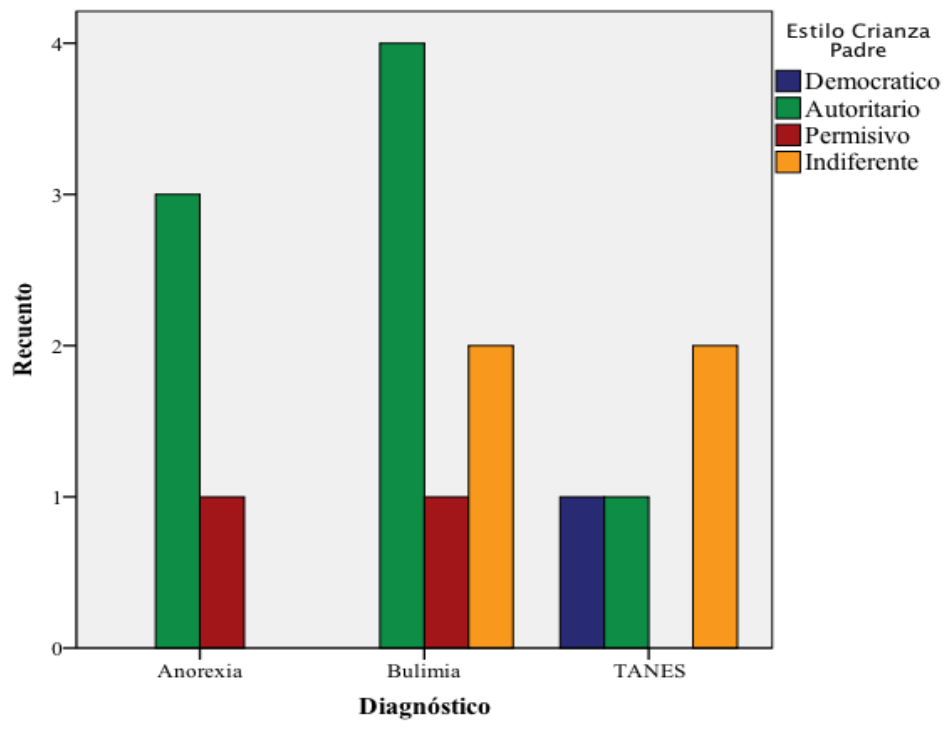

Gráfico 5. Estilo de Crianza paterno y Trastornos de la Conducta Alimentaria

Tanto en el Gráfico 4 como en el Gráfico 5 y en la Tabla 5 y Tabla 6, se puede observar la distribución de los Estilos de Crianza en cada Patología Alimentaria. A partir de estos se observaron diferencias significativas en lo que respecta al Estilo de Crianza, tanto materno como paterno y a su vez se observaron discrepancias en los Estilos en cada uno de los Trastornos Alimentarios.

Con respecto a los estilos percibidos en las madres, la mayor percepción del Estilo Democrático fue en el caso de las pacientes bulímicas, no encontrándose registro alguno en los otros dos tipos de patologías alimentarias. En lo que hace al Estilo Autoritario, este se halló presente en todos los casos, siendo más prevalente en las pacientes con TANES. El Estilo Permisivo fue mayormente percibido por las pacientes anoréxicas y en menor medida por las pacientes bulímicas, no se halló percepción del mismo en los TANES.

En función de los Estilos de Crianza percibidos en los padres, se pudo observar que el Estilo Democrático fue percibido únicamente por las pacientes con TANES. El Estilo Autoritario, al igual que en el caso de las madres, fue percibido en las tres Patologías Alimentarias, siendo más prevalente en las pacientes anoréxicas. Con respecto al Estilo Permisivo, se pudo vislumbrar que fue percibido mayormente también por las pacientes con Anorexia, siendo menor el porcentaje en las pacientes bulímicas. Por último, en lo que hace al Estilo Indiferente, se pudo observar que el mismo fue percibido principalmente en el caso de las pacientes con TANES y en menor proporción en las pacientes bulímicas.

El objetivo general de esta investigación fue caracterizar la percepción que tienen las pacientes con un Trastorno de la Conducta Alimentaria del Estilo de Crianza prevalente en su entorno familiar, e investigar cómo podría asociarse esto con el desarrollo de la patología. Si bien no se encontró completa unanimidad en las percepciones que tuvieron las pacientes que padecen la misma patología, se podría decir que las pacientes con un Trastorno Anoréxico percibieron en su mayoría un Estilo de Crianza, tanto materno como paterno, Permisivo. En lo que respecta al Trastorno Bulímico, la percepción de 
las pacientes estuvo dividida, osciló entre el Estilo de Crianza Materno Democrático y Autoritario. Y en cuanto al Estilo de Crianza Paterno percibido por este último grupo de pacientes, prevaleció el Estilo Autoritario. Si se intenta aunar resultados, se puede decir que en la Bulimia predominó la percepción de un Estilo de Crianza parental Autoritario. Y por último en los TANES, la percepción del Estilo de Crianza Materno estuvo también dividida entre el Estilo Autoritario e Indiferente, mientras que en el Estilo de Crianza Paterno predominó la percepción del Estilo Indiferente, nuevamente si se intenta unificar los resultados en el entorno familiar de las pacientes con TANES reina el Estilo de Crianza Indiferente.

En función de estos resultados y dando respuesta a la segunda cuestión que se propone investigar el presente estudio, cómo se asocia el Estilo de Crianza con el desarrollo de la Patología Alimentaria y analizar las diferencias existentes en cuanto a los Estilos de Crianza en los distintos cuadros de TCA. Se podría decir que, en el caso de las pacientes anoréxicas, el Estilo Permisivo estaría asociado al desarrollo del trastorno dado que estas pacientes suelen caracterizarse por tener un perfil más obsesivo, con un alto nivel de exigencia y perfeccionismo, sus padres las suelen describir como hijas perfectas. Probablemente este aspecto que opera a nivel inconsciente, no les permita percibir objetivamente el estilo de sus padres, con motivo de mantener este nivel de perfección inclusive a nivel familiar, quedando esta percepción sesgada por esta cuestión, por lo que en este caso no se podrían tomar los resultados hallados como material estrictamente objetivo y válido. En las pacientes que padecen Bulimia, la prevalencia del Estilo Autoritario podría asociarse con el desarrollo de la patología en el sentido que al haber tanto control y exigencias de madurez en el entorno familiar, y poco lugar a la comunicación e intercambio, estas pacientes encontrarían como vía de escape de esta situación el descontrol y desborde que las suele caracterizar. Finalmente, en el caso de las pacientes con TANES, el Estilo Indiferente se relacionaría al desarrollo del trastorno, en función de que la indiferencia e inestabilidad que perciben estas pacientes por parte de sus padres que las dejan como a la deriva, las lleva a encontrar como salida un trastorno que se caracteriza por lo mismo, por la inconsistencia, estarían repitiendo lo que percibieron y aprendieron a lo largo de su infancia.

En relación con el material obtenido de las entrevistas con los profesionales que atienden a las pacientes en el Instituto, tanto el psicólogo, como la nutricionista, como el medico clínico, cabe destacar los resultados a los que se llegó en cuanto la colaboración de los padres en el tratamiento de sus hijas. Los resultados alcanzados se pueden observar tanto en la Tabla 7 como en el Gráfico 6. En coherencia con los resultados descriptos anteriormente, con total unanimidad los padres no colaboradores pertenecieron a las pacientes con TANES, esto se condice con el Estilo de Crianza que caracteriza en general a los padres de este grupo de pacientes que es el Estilo Indiferente. Es por eso que los resultados obtenidos tendrían lógica, ya que estos padres al dejar a sus hijas a la deriva son como padres negligentes que poco se ocupan de ellas y por lo tanto de su tratamiento, no colaborando con el mismo. Por su lado en las otras dos patologías, tanto en la Anorexia como en la Bulimia, en todos los casos los padres a pesar de las dificultades que presentan, se mostraron colaboradores, siendo esto un aspecto esencial para la evolución exitosa del tratamiento. 


\begin{tabular}{|c|c|c|}
\hline & Colaboradores & No Colaboradores \\
\hline Anorexia & 4 & 0 \\
Bulimia & 8 & 0 \\
TANES & 0 & 4 \\
\hline
\end{tabular}

Tabla 7. Colaboración de los padres en el tratamiento.

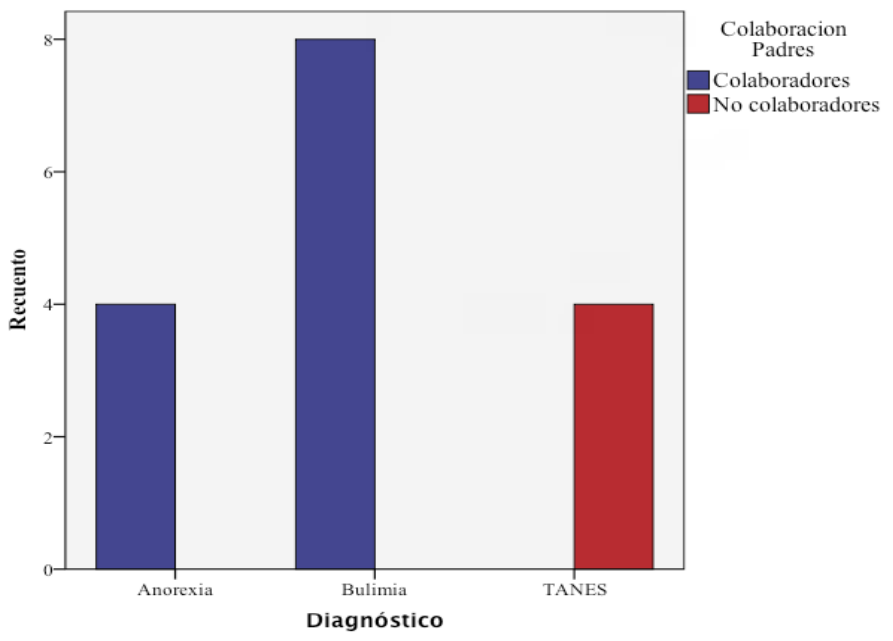

Gráfico 6. Colaboración de los padres en el tratamiento

A su vez de estas mismas entrevistas se pudo observar que si bien existen diversos factores desencadenantes de cada uno de los trastornos, la mayor prevalencia se dio en el ámbito familiar, esto reforzaría la motivación que determinó el llevar a cabo esta investigación, analizar los Estilos de Crianza de las pacientes según su Patología Alimentaria, dado el nivel de incidencia que tienen en el desarrollo de las mismas. Además de aquí se desprende y se vuelve a afirmar la necesidad de trabajar en conjunto con la familia en este tipo de trastornos, tal como se planteó en el comienzo de este estudio. Otro dato relevante es la elevada cifra de trastornos que tienen como factor desencadenante el abuso sexual, siendo esto una posible futura línea investigación.

\begin{tabular}{|c|c|c|c|c|c|}
\hline & Familia & Pares & Muerte/Duelo & $\begin{array}{c}\text { Abuso } \\
\text { Sexual }\end{array}$ & $\begin{array}{c}\text { No hay factor } \\
\text { desencadenante }\end{array}$ \\
\hline Anorexia & 2 & 0 & 0 & 1 & 1 \\
Bulimia & 2 & 1 & 1 & 3 & 1 \\
TANES & 3 & 0 & 0 & 0 & 1 \\
\hline Total & 7 & 1 & 1 & 4 & 3 \\
\hline
\end{tabular}

Tabla 8. Factor desencadenante del Trastorno Alimentario 


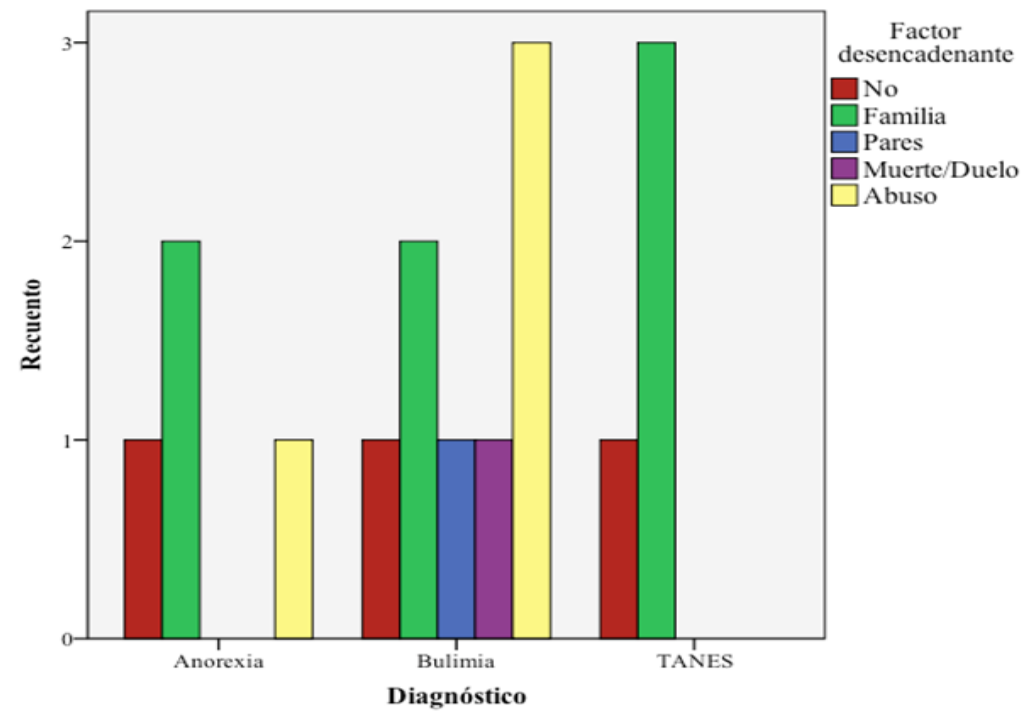

Gráfico 7. Factor desencadenante del Trastorno Alimentario

\section{Discusión}

Los Trastornos de la Conducta Alimentaria constituyen una problemática muy candente en la Argentina, siendo hoy en día unas de las patologías más consultadas y que llegan con mayor frecuencia a los hospitales y consultorios. Actualmente se puede observar una mayor prevalencia de los Trastornos No Especificados de la Conducta Alimentaria, quedando relegados a un segundo plano los trastornos puros. Esto quizás tenga que ver con la mutación que fueron sufriendo los trastornos originales en el tiempo por la aparición de nuevas desviaciones de la conducta alimentaria, existiendo hoy una gran cantidad de patologías que aún están siendo estudiadas y clasificadas.

En este apartado se describen las conclusiones de los resultados obtenidos en el presente estudio, relacionándolos con otras investigaciones afines desde la perspectiva teórica. Las conclusiones de esta investigación darían cuenta acerca de la relación existente entre los Trastornos de la Conducta Alimentaria y los Estilos de Crianza.

En primer lugar, cabe destacar que se cumplió la hipótesis planteada en un comienzo, existen diferencias en la percepción del Estilo de Crianza en función del tipo de Trastorno de la Conducta Alimentaria. Siguiendo la postura de Richaud de Minzi (2002), quien hace hincapié en que en realidad la capacidad de adaptación de una persona depende más de la percepción que ésta tiene acerca del comportamiento de su madre o padre, que del comportamiento "real" de sus progenitores, se intentó evaluar esto en la muestra. Se halló que en la Anorexia prevalece la percepción de un Estilo Permisivo, en la Bulimia un Estilo Autoritario y en el Trastorno Alimentario No Especificado un Estilo Indiferente.

Según Baumrind (1973) el Estilo de Crianza Democrático es el que mejor promueve el desarrollo de la personalidad en los hijos, brindándole seguridad y confianza en ellos mismos, así como habilidades comunicacionales y de socialización. Por lo que se podría decir que los otros tres estilos, tanto el Autoritario, como el Permisivo, como el Indife- 
rente serían en algún punto disfuncionales. Justamente los tres estilos que percibieron las pacientes con un Trastorno Alimentario son estos tres últimos, por lo que se podría concluir que la disfunción de los Estilos de Crianza ejercidos por estos padres estaría asociada al desarrollo de la patología. Ortíz Gómez (1999), asevera esto diciendo que la disfuncionalidad en una familia puede dar lugar al desarrollo de determinados síntomas, al desenlace de crisis o incluso puede agravar algún trastorno ya presente, haciendo que este se consolide, volviéndose así crónico. Por su lado Osorio-Murillo \& Amaya-Rey (2011), rectifican esto sosteniendo que la familia tiene una gran influencia en las creencias, en las prácticas y en la elección y consumo de los alimentos, es la creadora de las pautas de comportamiento en la alimentación, es por eso que los trastornos alimentarios podrían entenderse como un síntoma de la disfunción familiar cuanto mayor es la disfunción más grave sería el trastorno.

$\mathrm{Si}$ se analizan los resultados obtenidos en cada caso, en materia de los TANES prepondera un Estilo de Crianza Indiferente, esto podría tener su lógica en el sentido de que los padres con un Estilo Indiferente se caracterizan por ser indiferentes ante sus hijos, no son ni exigentes ni receptivos, no ejercen ningún tipo de control ni exigencias de madurez y los niveles de comunicación y afecto son muy bajos, dejando así a sus hijos a la deriva. Son padres negligentes, les dan a sus hijos tan poco como lo que les exigen. Según D. D. Jackson (1971), el nińo aprende a utilizar a sus padres como modelos de la manera en que se debe responder, es así que en este caso las pacientes con TANES estarían respondiendo según lo que aprendieron de sus progenitores, encontrando como vía de salida a esta situación de indiferencia el Trastorno Alimentario No Especificado que se caracteriza por la inestabilidad e inconsistencia, no tiene criterios estables sino al contrario no cumple con determinados criterios es por eso que se lo llama no especificado.

En el caso de la Anorexia, la cual se define por un alto nivel de exigencia, una búsqueda implacable de perfección, no sólo en su cuerpo sino en todo lo que se realiza, manteniendo muy buen rendimiento escolar, mientras sus condiciones psicofísicas se lo permiten. Tienen una imperiosa necesidad de completar los mandatos de sus padres que responden a esta imagen de perfección que los progenitores tienen de sus hijas, quienes suelen describirlas como "hijas perfectas". Provienen de familias con altos niveles de exigencia, sobre todo hacia esta hija en particular. Presentan una alteración en la imagen corporal. A la vez que presentan un peso bajo, mantienen la intención de seguir bajando y además se niegan a alimentarse. Esto en algún punto podría resultar contradictorio, ya que los padres de estas pacientes como se dijo antes les exigen mucho a sus hijas, lo cual no se condice con las características del Estilo Permisivo percibido por la muestra como preponderante en este grupo. Esto podría explicarse en función de esta búsqueda implacable de perfección a la que apuntan las pacientes anoréxicas, quienes poseen un superyó severo y excesivamente riguroso que opera a nivel inconsciente no permitiéndoles percibir la exigencia proveniente de su entorno familiar, naturalizando la situación y además percibiéndolos como padres permisivos. Estos padres se caracterizan por ejercer poco control y tener bajas exigencias de madurez, pero con un alto nivel de comunicación y afecto. Prima el "dejar hacer", aceptan la conducta de su hijo y no le ponen límites ni castigo, no hay normas que estructuren la vida del niño, sino que por el contrario consultan a sus hijos sobre decisiones, rechazando el ejercicio de poder y de control sobre el mismo. Brunch (1973), por su lado resalta que en los casos de Anorexia, existe entre la madre y la hija una relación temprana especial, en la cual hay un déficit de respuesta por parte de la madre ante las necesidades de la niña, esto tendría una mayor coherencia con el Estilo 
Permisivo percibido, ya que como se dijo antes en este estilo prima el "dejar hacer", sin que haya límite alguno que oriente y estructure la vida de estas pacientes, dando lugar a que éstas lo perciban como una falta de respuesta ante sus necesidades, dado que los limites son necesarios para crecer.

Por último, en el caso de la Bulimia impera un Estilo de Crianza Autoritario, podría explicarse esto en función de lo que sostienen Pole, Waller, Stewart \& Parkin-Feigenbaum (1988) quienes concluyeron que los síntomas bulímicos estarían encubriendo un déficit del ego y esto estaría relacionado a su vez con una pobre empatía parental. Los padres que ejercen un Estilo Autoritario se definen por ejercer un estricto control y exigir un elevado nivel de madurez a sus hijos, lo que va acompañado de una pobre comunicación y escasa expresión emocional. Lo que caracteriza a este patrón de crianza son las excesivas normas y las exigencias estrictas, las cuales están basadas en patrones rígidos preestablecidos y les cuesta moverse de ellos. Prima la obediencia de las normas y en caso de no cumplirse, recurren al uso del castigo sin dar lugar alguno al diálogo ni a la empatía. Las pacientes bulímicas según la Asociación Psiquiátrica Americana (2002) se caracterizan por la recurrencia y repetitividad de episodios en los que el enfermo come de manera excesiva y desproporcionada (atracones) una cantidad de comida mucho mayor a la que comería la mayoría de la gente en un período muy corto de tiempo. Luego intenta compensar esto, recurriendo a diferentes tipos de conductas purgativas inapropiadas, como el vómito autoinducido, el abuso de laxantes y diuréticos, el ayuno drástico y/o el hacer ejercicio compulsivamente, con el fin de controlar su peso. Este grupo a diferencia de las anoréxicas donde prima la búsqueda de perfección, se suele caracterizar por practicar un estilo de vida mas descontrolado, donde predomina el descontrol y el desenfreno, esto podría entenderse como una conducta reactiva ante el excesivo control percibido por ellas como proveniente de sus padres, encontrando como vía de escape las conductas compensatorias inadecuadas practicadas por las mismas, donde las pacientes encuentran un gran alivio y que constituyen un aspecto fundamental que caracteriza a este cuadro.

El presente estudio pretende aportar elementos para ser incluidos en un modelo de intervención en pacientes con Trastornos de la Conducta Alimentaria. Es importante tomar en consideración todo lo dicho previamente cuando se trabaja desde la clínica, es decir cuando se está frente a un paciente con diagnóstico de patología alimentaria, dado que según los resultados obtenidos es un aspecto esencial en el tratamiento psicológico de estos pacientes el hecho de trabajar en conjunto con la familia, tanto para poder comprender la etiología del cuadro, como para lograr una evolución exitosa.

\section{Puntos Fuertes, Limitaciones y Futuras Líneas de Estudio}

Cabe destacar como punto fuerte de esta investigación el hecho de que se cumpla la hipótesis planteada en un principio, es decir que exista un Estilo de Crianza prevalente en cada Patología Alimentaria. Además, es una investigación innovadora en la temática, dado los pocos estudios que traten a estas dos variables juntas.

En cuanto a las limitaciones, es importante mencionar el hecho de que en este estudio se investigó las percepciones que tienen las pacientes del Estilo de Crianza prevalente en cada Trastorno Alimentario, siendo estas percepciones subjetivas, por lo que los resultados obtenidos no se podrían tomar como verdades absolutas y objetivas. Si bien fueron 
muy útiles para esta investigación en particular, la cual apuntaba a este objetivo, cabe considerar que pueden no ser válidos para otras investigaciones. Otra limitación proviene del hecho de que la muestra es demasiado pequeña como para generalizar los resultados a la totalidad de las pacientes con patologías alimentarias, sumándose a esto el hecho de que todos los pacientes provienen del mismo lugar, del Instituto Argentino de Trastornos de la Alimentación. Para que esto sea posible debería ampliarse la muestra en número de casos y a su vez sería interesante que provengan de diversas instituciones y países.

Conocer estos datos acerca de los Estilos de Crianza, podría contribuir para investigaciones futuras que apunten a desarrollar algún programa de prevención para las familias contra los Trastornos Alimentarios. Además, en función de los resultados obtenidos en cuanto a los factores desencadenantes de las patologías, se pudo observar la elevada cifra de casos que fueron desencadenados a partir de abusos sexuales, por lo que este hecho sería un punto interesante e importante para investigar en futuras líneas de estudio.

\section{Bibliografía}

— Alberto \& Ortego M. A. (2006). Un estudio sobre personalidad, ansiedad y depresión en padres de pacientes con un trastorno alimentario. Clínica y Salud, 17(2), 151-170.

- American Psychiatric Association. (1993). Diagnostic and Statistical Manual of Mental Disorders (4th ed.). Washington, D.C: American Psychiatric Association.

- Brunch H. (1973). Eating disorders: Obesity, anorexia and the person within. New York. Basic Books.

— Ceballos E. \& Rodrigo M. J. (1998). Las metas y estrategias de socialización entre padres e hijos. En Rodrigo M. J. \& Palacios J. (1998), Familia y desarrollo humano. España. Alianza.

— Coll C., Miras M., Onrubia J. \& Solé I. (1998). Psicología de la Educación. Barcelona: Edhasa.

- Cruzat C., Aspillaga C., Torres M., Rodríguez M., Díaz M. y Haemmerli C. (2010). Significados y vivencias subjetivas asociados a la presencia de un trastorno de la conducta alimentaria, desde la perspectiva de mujeres que lo padecen. Psykhe, 19(1), 3-17.

— Cruzat C., Ramirez P., Melpillán R. \& Marzolo P. (2008). Trastornos Alimentarios y Funcionamiento Familiar Percibido en una Muestra de Estudiantes Secundarias de la Comuna de Concepción, Chile. Psykhe, 17(1), 81-90.

- Cuervo Martínez A. (2010). Pautas de crianza y desarrollo socioafectivo en la infancia. Revista Diversitas - Perspectivas en Psicología, 6 (1), 111-121.

- Espina A. (2003). Alexithymia in parents of daughters with eating disorders. Its relationships with psychopathological and personality variables. Journal of Psychosomatic Research, 55 (6), 553-560.

- Espina Eizaguirre (2005). La figura del padre en los trastornos de la conducta alimentaria. Familia, 31, 35-48.

— Espina Eizaguirre A., Ochoa de Alda Martínez de Apellániz I. \& Ortego Saenz de Cabezón M. A. (2007). Conductas alimentarias, salud mental y estilos de crianza en adolescentes de Gipuzkoa. D'Elikatuz Bizi. 
— Gedo J. E. y Goldberg A. (1973). Models of the mind. Chicago: University of Chicago Press.

- Henao G., Ramírez C. y Ramírez L. (2007). Las prácticas educativas familiares como facilitadoras del proceso de desarrollo del niño y niña. El Ágora, 7 (2), 233240.

- Humphrey L. L. y Stern S. (1988). Object relations and the family system in bulimia: a theoretical integration. Journal of Marital and Family therapy, 14(4), 337-350.

—Jackson D. D. (1971). Interacción familiar, homeostasis familiar y psicoterapi a familiar conjunta. En G. Bateson, A. J. Ferreira, D. D. Jackson, T. Lidz, J. Weakland, L. C. Wynne \& G. Zuk, Interacción familiar. Aportes fundamentales sobre teoría y técnica (pp. 164-195). Buenos Aires, Argentina: Editorial Tiempo Contemporáneo.

— Larraín M. E., Zegers B., Díez I. \& Trapp A. (2003). Validez y Confiabilidad de la Versión Española de la Escala del Estilo de Funcionamiento Familiar (EFF) de Dunst, Trivette \& Deal para el Diagnóstico del Funcionamiento Familiar en la Población Chilena. Psykhe, 12(1), 195-211.

— Leija Esparza M., Sauceda García J. M. \& Ulloa Flores R. E. (2011). Características familiares y trastornos de la conducta alimentaria en una muestra de mujeres adolescentes internadas en un hospital psiquiátrico. Salud Mental, 34(3), 203210.

- Mestre M. V., Tur A. M., Samper P., Nácher M. J. y Cortés M. T. (2007). Estilos de crianza en la adolescencia y su relación con el comportamiento prosocial. Revista Latinoamericana de Psicología, 39 (2), 211-225.

- Moreno B. A. F. \& Kusmin P. (1970). Tratamiento de las crisis familiares. En C. E. Sluzki, I. Berenstein, H. B. Bleichman \& I. Maldonado Allende, Patología y terapéutica del grupo familiar (pp. 169-171). Buenos Aires, Argentina: Acta, Fondo para la salud mental.

— Ortíz Gómez M. T. (1999). La Salud Familiar. Revista Cubana de Medicina General Integral, 15(4), 439-445.

- Osorio-Murillo O. \& Amaya-Rey M. C. P. (2011). La alimentación de los adolescentes: el lugar y la compañía determinan las prácticas alimentarias. Aquichan, 11(2), 199-216.

- Pichon-Riviere E. J. (1970). Una teoria del abordaje de la prevención en el grupo familiar. En C. E. Sluzki, I. Berenstein, H. B. Bleichman \& I. Maldonado Allende, Patología y terapéutica del grupo familiar (pp. 136-140). Buenos Aires, Argentina: Acta, Fondo para la salud mental.

— Pole R., Waller D., Stewart S., Parkin y Feigenbaum L. (1988). Parental caring versus overprotection in bulimia. International Journal of Eating Disorders, 7 (5), 601-606.

- Ramírez M. A. (2005). Padres y desarrollo de los hijos: prácticas de crianza. Estudios Pedagógicos, 31 (2), 167-177.

- Rhodes B. y Kroger J. (1992). Parental bonding and separation-individuation difficulties among late adolescent eating disordered women. Child Psychiatry and Human Development, 22, 249-263. 
— Richaud de Minzi M. C. (2002). Inventario acerca de la Percepción que tienen los Niños y las Niñas de las relaciones con sus Padres y Madres: Versión para 4 a 6 años. Revista Interamericana de Psicología, 36 (1\&2), 149-165.

- Ruíz-Martínez A. O., Vazquez-Arevalo R., Mancilla-Díaz J. M., López-Aguilar X. Álvarez-Rayón G. \& Tena-Suck A. (2010). Funcionamiento familiar en el riesgo y la protección de trastornos del comportamiento alimentario. Universitas Psychologica, 9(2), 447-455.

- Russell J., Kopec-Schrader E., Rey E. y Beumont P. (1992). Parental bonding instrument in adolescent patiens with anorexia nervosa. Acta Psychiatryca Scandinavica, 86, 236-239.

— Selvini Palazzoli M., Cirillo C., Selvini M. y Sorrentino A. M. (1999). Muchachas anoréxicas y bulímicas. Paidos: Barcelona.

— Stierling H. y Weber G. (1987). Anorexia nervosa: family dynamics and family therapy. En Beaumont P., Burrows G. y Casper C. (eds.). Handbook of eating disorders. Part 1: anorexia and bulimia nervosa. Amsterdam: Elsevier.

— Torío S., Peña J. y Caro M. (2008). Estilos de educación familiar. Psicothema, 20 (1), 62-70.

- Vandereycken W., Castro J. y Vanderlinden J. (1991). Anorexia y Bulimia: La familia en su génesis y tratamiento. Martínez Roca: Barcelona.

\section{Índice de Cuadros y Tablas}

Tabla 1. Diagnósticos de las pacientes.

p. 98

Tabla 2. Edad.

p. 98

Tabla 3. Inicio del tratamiento.

p. 100

Tabla 4. Estilos de Crianza materno.

y paterno en cada caso según diagnóstico.

p. 101

Tabla 5. Estilo de Crianza materno y Patologias Alimentarias.

p. 102

Tabla 6. Estilo de Crianza paterno y Patologias Alimentarias.

Tabla 7. Colaboración de los padres en el tratamiento.

p. 103

Tabla 8. Factor desencadenante del Trastorno Alimentario.

p. 106

p. 106

\section{Índice de Gráficos}

Gráfico 1. Distribución de los diagnósticos.

p. 98

Gráfico 2. Edad.

p. 99

Gráfico 3. Inicio del tratamiento.

Gráfico 4. Estilo de Crianza materno y

p. 100

Trastornos de la Conducta Alimentaria.

p. 103

Gráfico 5. Estilo de Crianza paterno y

Trastornos de la Conducta Alimentaria.

p. 104

Gráfico 6. Colaboración de los padres en el tratamiento.

p. 106

Gráfico 7. Factor desencadenante del Trastorno Alimentario.

p. 107 